Full length article

\title{
Laparoscopic sacrocolpopexy as the mainstay management for significant apical pelvic organ prolapse (LAP) study
}

\author{
Vladimir Kalis $^{\mathrm{a}, \mathrm{b}}$, Martin Smazinka ${ }^{\mathrm{b}}$, Zdenek Rusavy $^{\mathrm{a}, \mathrm{b}}$, Mija Blaganje $^{\mathrm{c}}$, Martin Havir ${ }^{\mathrm{b}}$, \\ Linda Havelkova ${ }^{\mathrm{d}}$, Khaled Ismail ${ }^{\mathrm{a}, \mathrm{e}, *}$
}

a Biomedical Center, Faculty of Medicine in Pilsen, Charles University, Czech Republic

${ }^{\mathrm{b}}$ Department of Obstetrics and Gynecology, University Hospital, Pilsen, Czech Republic

${ }^{\mathrm{c}}$ Divison of Gynecology, University Medical Centre Ljubljana, Slovenia

${ }^{\mathrm{d}}$ New Technologies - Research Centre, University of West Bohemia, Czech Republic

${ }^{\mathbf{e}}$ Department of Gynecology and Obstetrics, Faculty of Medicine in Pilsen, Charles University, Czech Republic

\section{A R T I C L E I N F O}

\section{Article history:}

Received 29 July 2019

Received in revised form 29 October 2019

Accepted 31 October 2019

Available online $\mathrm{xxx}$

\section{Keywords:}

ASA-PS

Feasibility

POP

Repair

Outcomes

\begin{abstract}
A B S T R A C T
Study objectives: The primary aim of this study was to assess the clinical feasibility of a policy where laparoscopic sacrocolpopexy (LSC) is the default procedure for the management of a significant apical pelvic organ prolapse (a-POP). As a secondary aim, we wanted to evaluate LSC outcomes in relation to women's preoperative assessment of their surgical fitness using the American Society of Anesthesiologists physical status (ASA-PS) categorization.

Design: Retrospective cohort study.

Setting: A university affiliated urogynecology center.

Methods: All women with symptomatic a-POP $(C \geq-1)$ who attended the urogynecology clinic between the $1^{\text {st }}$ of January and the $31^{\text {st }}$ of December 2016 and had their surgery by the $31^{\text {st }}$ of May 2017 were included in the study. In our unit, routine follow-up appointments are arranged at 3 and 12 months post LSC.

Interventions: Perioperative and mesh-related complications were assessed based on the Dindo-Clavien and IUGA/ICS classifications respectively. The preoperative outcome measures included Pelvic Organ Prolapse Quantification (POP-Q) stage, Pelvic Floor Distress Inventory (PFDI) and ASA-PS score. At followup women were asked to complete a PFDI, Patient Global Impression of Improvement (PGI-I), had their POP-Q staging and ultrasonographic assessment of mesh position and placement. The above measures are routinely collected as part of our standard practice. A preoperative ASA-PS score of $<3$ was used as a cut-off to dichotomies participants into low and high risk.

Main results: A total of 220 women attended our center during the study period because of POP. Of these, 146 women were diagnosed with a significant a-POP and 142 (97.2\%) women opted for a surgical repair. Of the 142 women, 128 (90.1 \%) were deemed suitable for a type of LSC and 121 had their surgery before the $31^{\text {st }}$ of May 2017. There were no statistically significant differences in any of our collected perioperative, clinical, patient reported or ultrasonographic outcome measures when comparing women with ASA-PS scores of $<3$ or $>3$. Conclusion: In a specialized urogynecology healthcare setting, it is feasible and safe to rely on LSC as the mainstay surgical procedure for the repair of a significant a-POP. However, it is imperative to ensure that technical skills and equipment requirements are fulfilled and maintained.
\end{abstract}

(c) 2019 Elsevier B.V. All rights reserved.

\section{Introduction}

Pelvic organ prolapse (POP) is a frequent and disabling condition for women with a debilitating effect on their quality

\footnotetext{
* Corresponding author at: Department of Gynecology and Obstetrics, Faculty of Medicine in Pilsen, Charles University, alej Svobody 80, 30460 Pilsen, Czech Republic.

E-mail address: khaled.ismail@lfp.cuni.cz (K. Ismail).
}

of life [1-3]. There have been several treatment options for POP with a dominant apical defect (a-POP) including sacrocolpopexy, vaginal mesh procedures and native tissue repairs [4-6]. There is high-level evidence documenting that laparoscopic sacrocolpopexy (LSC) achieves superior clinical outcomes, compared to other procedures, amongst women with a preoperative Pelvic Organ Prolapse Quantification (POP-Q) apical stages 2-4 [5]. Moreover, the use of vaginal mesh procedures and native tissue repair procedures are limited by the recent FDA ban on their use and higher rates of recurrence respectively [7-12]. Therefore, currently, 
sacrocolpopexy is considered the gold standard procedure for the management of a significant a-POP $[13,14]$. However, the potentially longer operative procedure and the cardiopulmonary stress posed by the association of extreme Trendelenburg position and pneumoperitoneum are sometimes deterrents for clinicians to offer the procedure as a treatment option $[15,16]$.

There is paucity of information evaluating the outcomes of the different surgical procedures for a-POP in relation to the general patient pre-operative risk. Therefore, there is a high level of subjectivity in offering these procedures and hence a wide variation in the rates at which this treatment modality is offered in different centers. In our center LSC is considered as the default surgical option for managing symptomatic stage 2 , or higher, a-POP. The primary aim of this study was to assess the clinical feasibility of a policy where LSC is the default procedure for the management of a significant a-POP. As a secondary aim, we wanted to evaluate LSC outcomes based on the woman's preoperative ASA-PS categorization.

\section{Materials and methods}

All women with symptomatic a-POP $(\mathrm{C} \geq-1)$ according to the POP-Q classification [17] who attended our urogynecology clinic between the $1^{\text {st }}$ of January and the $31^{\text {st }}$ of December 2016 and had their surgery by the $31^{\text {st }}$ of May 2017 were included in the study. The local ethics committee approved the study including retrospective anonymized data collection without the need for a written consent.

\section{Pre-operative assessment}

In our center, women with a significant a-POP undergo a clinical assessment by one of four urogynecology specialists which includes the patient's medical history, clinical examination, POP$\mathrm{Q}$ measurement and a pelvic floor ultrasound scan. It is our routine practice that women considered for LSC are assessed for their fitness for surgery by a senior anesthesiologist using the American Society of Anesthesiologists Physical Status (ASA-PS) classification system. ASA-PS is a validated tool that is widely used for the assessment of patients' preoperative morbidity. This classification stratifies patients into one of 5 categories: 1 = "a normal healthy patient"; 2 = "a patient with mild systemic disease"; 3 = "a patient with severe systemic disease"; 4 = "a patient with severe systemic disease that is a consistent threat to life"; 5 = "a moribund patient that is not expected to survive without an operation" [18]. Women deemed suitable for the procedure are listed and asked to complete a Pelvic Floor Distress Inventory (PFDI) [19].

\section{Operative procedure}

LSCs were performed by one of four urogynecology specialists. A type 1, large pore monofilament polypropylene mesh (Bard ${ }^{\mathbb{R}} \mathrm{Soft}$ Mesh, Davol Inc., Subsidiary of C. R. Bard, Inc.; 100 Crossings Boulevard, Warwick, RI 02,886) was used. An inverted "Y"-shaped mesh was used to treat the vaginal prolapse after a previous hysterectomy, or in cases of concomitant total or subtotal hysterectomy. However, two separate mesh straps were used for sacrohysterocolpopexy, an anterior "Y"-shaped and a posterior "I"shaped mesh. The surgeon then fixed the upper ends of the strand (s) to the longitudinal anterior ligament just above the promontory using two non-resorbable size 1-0 Ti-Cron ${ }^{\mathrm{TM}}$ braided polyester sutures (Covidien, 555 Long Wharf Drive, New Haven, CT, 06,511). The peritoneum was closed over the mesh in each case.

\section{Follow-up}

In our unit, women are routinely sent follow-up appointments at 3 and 12 months post LSC for assessment of their symptoms, evaluation of any postoperative complications and clinical examination including a POP-Q measurement. They are also asked to complete a PFDI and their overall satisfaction with the surgical procedure is evaluated by means of a 7-point Patient Global Impression of Improvement (PGI-I) scale ranging from "Very much worse" (PGI-I =7) to "Very much better" (PGI-I=1) [20]. Mesh related complications were described using the current standardized international classification [21]. A 3D/4D transperineal ultrasound is also performed using a Voluson E8 ultrasound system (GE Medical Systems, Zipf, Austria) equipped with a 4$8 \mathrm{MHz} \mathrm{RAB}$ curved-array volume transducer (acquisition angle $85^{\circ}$ ). The position of the lowest part of individual compartments and the bladder neck at rest and Valsalva was measured in relation to a horizontal line at the level of the pubic symphysis. Volume acquisition was performed with the patient at rest and on maximal Valsalva, as described previously by Dietz et al. [22]. Mesh position and placement were additionally evaluated at 3 and 12 months. The lowest anterior mesh position relative to the horizontal line at the level of symphysis pubis at Valsalva and the distance of the inferior margin of the anterior mesh from the bladder neck at rest were determined [22]. Proper placement of the mesh was evaluated using the following composite criteria: distance of the lowest margin of the anterior mesh strand from the bladder neck $<20 \mathrm{~mm}$ [23]; regular shape of the mesh upon visualization of the whole mesh; no folding ; and vertical mesh descent on Valsalva not exceeding $20 \mathrm{~mm}$. Folding was defined as doubling over of mesh, creating at least two layers of mesh in one location [24].

Demographic details, data related to previous medical, perioperative details, surgical and sexual history were extracted from the hospital health records. Postoperative complications were categorized according to the Dindo-Clavien classification [25]. Statistical analysis was performed using SAS 9.4 (SAS Institute Inc., Cary, NC, USA) statistical software. Non-parametric ANOVA (2sample Wilcoxon test or 2-sample Median test), $\chi^{2}$ test or Fisher's exact test were used as appropriate. A p $<0.05$ was considered statistically significant. For the purpose of this study, anatomical success was defined as a postoperative POP-Q point $\mathrm{C}<-3 \mathrm{~cm}$ and points $\mathrm{Ba}$ and $\mathrm{Bp}<-1 \mathrm{~cm}$. While subjective success of the procedure was based on a PGI-I $<3$.

\section{Results}

A total of 220 women attended our center between the $1^{\text {st }}$ of January and $31^{\text {st }}$ of December 2016 having been referred because of a POP. Of these, 146 (66.3\%) women were diagnosed with a significant a-POP, two patients were offered conservative management in the form of a pessary and two women declined any further management leaving 142 (97.2\%) women who were offered a surgical repair for their a-POP. Of the 142 women who opted for a surgical repair, 128 (90.1\%) were deemed suitable for a type of LSC while the rest were considered for a different type of surgical repair (Fig.1 and supplementary material). Of the women who consented to have an LSC, 6 patients had their surgery planned after the $31^{\text {st }}$ of May and hence contributed to the feasibility of LSC as a potential treatment option calculation but not the procedure outcome analysis. One patient $(0.7 \%)$ who had a pre-existing rectovaginal fistula following radiotherapy for a colorectal malignancy was not included into the final analysis because, further to multidisciplinary discussion, it was decided to avoid attaching any mesh to the vagina. Moreover, her pre-existing condition was considered a major confounder to several of the patient reported outcomes considered in this study. The remaining 121 (82.9 \%) women underwent one of the following surgical procedures: laparoscopic sacrocolpopexy; laparoscopic subtotal hysterectomy (+/- salpingo-oophorectomy) and sacrocervicocolpopexy, sacrohysterocolpopexy; laparoscopic hysterectomy 


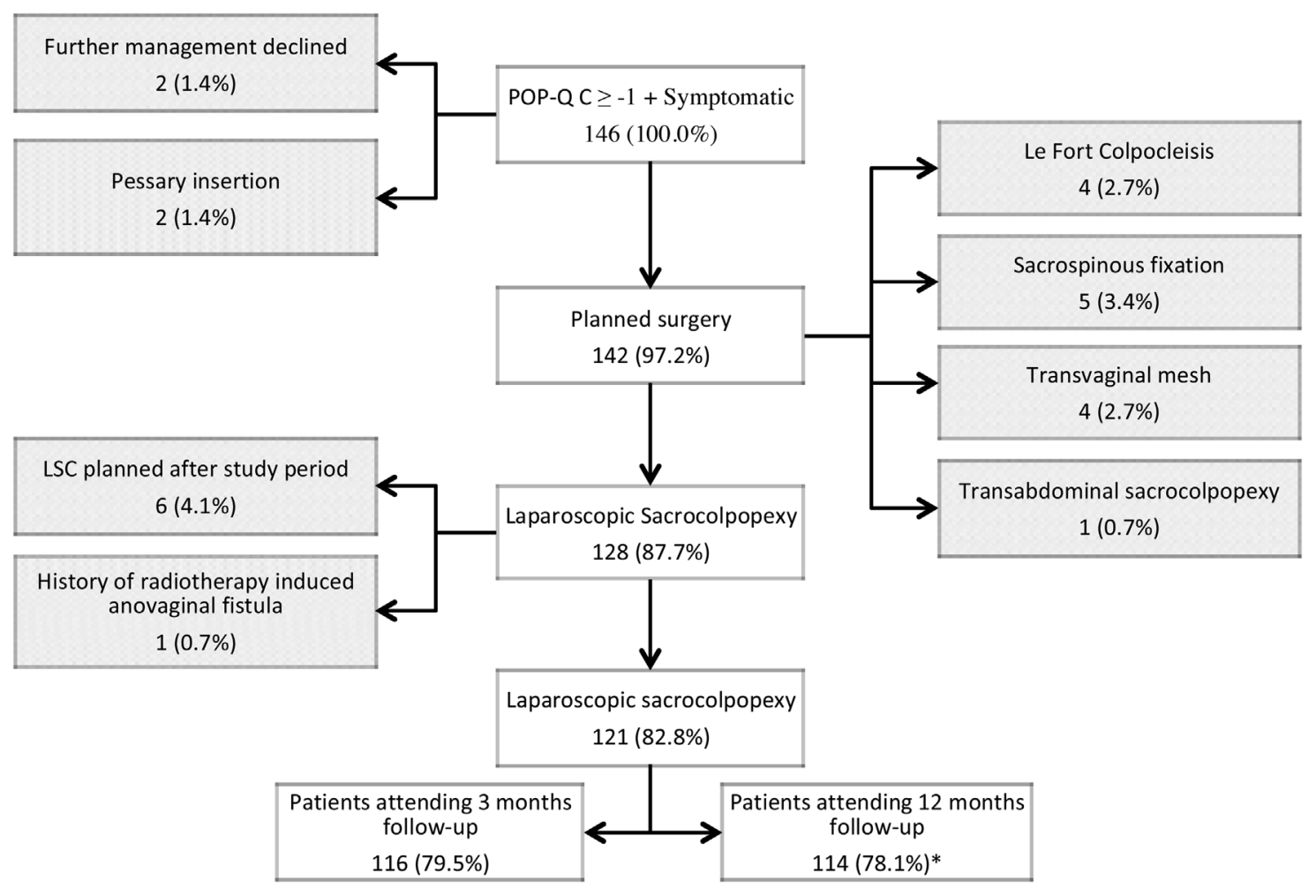

* Some patients only attended the 12 month follow-up appointment

Fig. 1. Study participants' flow chart.

(+/- salpingo-oophorectomy) and sacrocolpopexy (supplementary material). Our analysis for the clinical feasibility of the policy of LSC as the mainstay surgical procedure for a significant a-POP was based on the intention to treat, therefore $128 / 142$ (90.1\%) of the women with a significant a-POP were offered and consented for an LSC. All LSCs attempted during the study period were completed laparoscopically.

Grouping participants based on their preoperative ASA-PS level of $<3$ or $\geq 3$, as a surrogate for low or high anaesthetic risk respectively, demonstrated that the cohort of women with a preoperative ASA-PS $\geq 3$ significantly differed from those with a score of $<3$ in age, BMI and previous abdominal surgery (Table 1 ). As expected, there were more women with pre-existing diabetes and cardiovascular diseases. However, there were no statistically significant differences between the subgroups with regards to other pre-operative, operative (Table 2) or post-operative (Table 3 ) variables. There was one case of difficult intubation in each of the subgroups and three (2.5\%) documented bladder injuries in total. According to the Dindo-Clavien classification, there were 2 early complications, one (2.2\%) grade IIIB complication related to a right ureteric kink treated with a subsequent temporary ureteric stent and one (1.3\%) woman with a grade II complication where a blood transfusion was deemed required in the ASA-PS $\geq$ and $<3$ respectively (Table 2). There were no reported cases of ileus, wound infections, sepsis or rectal injuries.

Follow-up rates at three and 12 months and postoperative clinical and patient reported outcomes in both subgroups are presented in Table 3 . There were no significant postoperative differences in any of the analyzed variables. Three $(2.6 \%)$ meshrelated complications were recorded at twelve months - two (2.8 $\%)$ in the ASA-PS $<3$ subgroup and one $(2.4 \%)$ in the ASA-PS $\geq 3$ group. One woman in the ASA-PS $<3$ reported worsening of her symptoms twelve months after LSC. While two women (one in each group) reported that their overall condition remained unchanged, according to the PGI-I $(\mathrm{p}=.90)$. Based on POP-Q, there were no apical compartment failures (the maximum $C=-5$ ). However, at the twelve-month appointments there were $6(5.3$ $\%)$ anterior compartment (the maximum $\mathrm{Ba}=-1$ ), and 11 (9.6\%) posterior compartment (the maximum $\mathrm{Bp}=+1$ ) failures. Ultrasonographic measurements revealed that 7 (6.2 \%) and $10(8.7 \%)$ women had the lowest margin of the anterior mesh $\geq 20 \mathrm{~mm}$ from the bladder neck at 3 and 12 months respectively while this measurement was $<20 \mathrm{~mm}$ in the rest of the women at follow-up. This distance is important, as it has been shown that for every millimeter the mesh is located distal to the urethra-vesical junction, the likelihood of cystocele repair failure increases by 6-7\% [23]. All four selected criteria for a desired mesh placement were fulfilled in $92 / 105(87.6 \%)$ at three months and in $87 / 102$ $(85.3 \%)$ at one year and there were no statistically significant differences between the subgroups (Supplementary material).

\section{Discussion}

Evidence supporting the effectiveness of LSC for the management of significant a-POP is well established [5]. This issue is, particularly, more relevant following the FDA's ban on the selling and distribution of surgical mesh intended for the transvaginal repair of anterior compartment prolapse [7,8]. However, there is perceived wide variation in practice between centers regarding the frequency at which the procedure is being offered. The results of this retrospective study demonstrate that LSC is safe and feasible to be considered as the primary surgical procedure for the repair of a significant a-POP. Indeed, in this study we demonstrated that, during the study period, it was suitable for LSC to be offered and accepted in $90 \%$ of the cohort of women referred to our center with a symptomatic a-POP. 
Table 1

Demographic data of study participants categorized by their ASA-PS scores.

\begin{tabular}{|c|c|c|c|c|}
\hline \multicolumn{2}{|l|}{ Variable } & ASA PS $<3 \mathrm{~N}=75$ & ASA PS $\geq 3 \mathrm{~N}=46$ & $\mathrm{p}$ \\
\hline \multicolumn{2}{|c|}{ Age [Mean (SD)] } & $59.8(9.6)$ & $67.0(8.3)$ & $0.0001^{\mathrm{a}}$ \\
\hline \multicolumn{2}{|c|}{ Parity [Mean (SD)] } & $2.0(0.8)$ & $2.1(0.8)$ & $0.37^{\mathrm{b}}$ \\
\hline \multicolumn{2}{|c|}{ BMI [Mean (SD)] } & $26.3(3.1)$ & $28.1(3.8)$ & $0.006^{\mathrm{a}}$ \\
\hline \multicolumn{2}{|c|}{ Previous abdominal surgical history N (\%) } & $41(54.7 \%)$ & $38(82.6 \%)$ & $0.002^{\mathrm{c}}$ \\
\hline \multicolumn{2}{|c|}{ Previous gynecologic surgery $\mathrm{N}(\%)$} & $39(52.0 \%)$ & $29(63.0 \%)$ & $0.23^{\mathrm{c}}$ \\
\hline \multicolumn{2}{|c|}{ Previous POP surgery N (\%) } & $7(9.3 \%)$ & $7(15.2 \%)$ & $0.33^{\mathrm{c}}$ \\
\hline \multirow[t]{4}{*}{ Point C } & POP Q stage I & $0(0.0 \%)$ & $0(0.0 \%)$ & $0.31^{\mathrm{c}}$ \\
\hline & POP Q stage II & $48(64.0 \%)$ & $23(50.0 \%)$ & \\
\hline & POP Q stage III & $17(22.7 \%)$ & $14(30.4 \%)$ & \\
\hline & POP Q stage IV & $10(13.3 \%)$ & $9(19.6 \%)$ & \\
\hline \multirow[t]{4}{*}{ Point Ba } & POP Q stage I & $0(0.0 \%)$ & $0(0.0 \%)$ & $0.71^{\mathrm{c}}$ \\
\hline & POP Q stage II & $16(21.3 \%)$ & $10(21.7 \%)$ & \\
\hline & POP Q stage III & $44(58.7 \%)$ & $24(52.2 \%)$ & \\
\hline & POP Q stage IV & $15(20.0 \%)$ & $12(26.1 \%)$ & \\
\hline \multirow[t]{4}{*}{ Point Bp } & POP Q stage I & $18(24.0 \%)$ & $9(19.6 \%)$ & $0.42^{\mathrm{C}}$ \\
\hline & POP Q stage II & $38(50.6 \%)$ & $19(41.2 \%)$ & \\
\hline & POP Q stage III & $11(14.7 \%)$ & $9(19.6 \%)$ & \\
\hline & POP Q stage IV & $8(10.7 \%)$ & $9(19.6 \%)$ & \\
\hline \multicolumn{2}{|c|}{ Stress urinary incontinence } & $23(30.7 \%)$ & $10(21.7 \%)$ & $0.28^{\mathrm{c}}$ \\
\hline \multicolumn{2}{|c|}{ Urge urinary incontinence } & $15(20.0 \%)$ & $14(30.4 \%)$ & $0.19^{c}$ \\
\hline \multicolumn{2}{|c|}{ Hesitancy: a delay in initiating micturition } & $30(40.0 \%)$ & $24(52.2 \%)$ & $0.19^{c}$ \\
\hline \multicolumn{2}{|c|}{ Urinary retention } & $35(50.0 \%)$ & $20(43.5 \%)$ & $0.73^{\mathrm{c}}$ \\
\hline \multicolumn{2}{|c|}{ Constipation N (\%) } & $18(24.0 \%)$ & $12(26.1 \%)$ & $0.80^{\mathrm{C}}$ \\
\hline \multicolumn{2}{|c|}{ Anal incontinence N (\%) } & $16(21.3 \%)$ & $8(17.4 \%)$ & $0.60^{c}$ \\
\hline \multicolumn{2}{|c|}{ Pre-op UDI mean (SD) } & $68.8(46.6)$ & $57.2(45.9)$ & $0.19^{\mathrm{a}}$ \\
\hline \multicolumn{2}{|c|}{ Pre-op POPDI mean (SD) } & $87.8(55.6)$ & $87.7(51.7)$ & $0.95^{\mathrm{a}}$ \\
\hline \multicolumn{2}{|c|}{ Pre-op CRADI mean (SD) } & $59.4(51.7)$ & $53.6(55.4)$ & $0.55^{\mathrm{a}}$ \\
\hline \multicolumn{2}{|c|}{ Pre-op PFDI mean (SD) } & $216.0(134.8)$ & $198.5(132.7)$ & $0.52^{\mathrm{a}}$ \\
\hline
\end{tabular}

BMI body mass index, DVT deep venous thromboembolism, ASA PS assessment of the patient's preoperative physical status [17], SD standard deviation.

a Wilcoxon Two Sample Test.

b Median Two Sample Test.

c Chi-square Test.

In this study we opted to stratify women according to their ASAPS score, which we used as an objective surrogate for their physical health and operative risk. We did not identify any significant differences between our stratified cohorts in their perioperative, clinical nor patient reported outcomes. We did not identify other studies that have assessed LSC outcomes in relation to ASA-PS scores to compare our results to. Nevertheless, there are several studies that assessed LSC operative outcomes in relation to women's age [26-29]. In a study by Turner and colleagues where participants had a mean age of 58.5 years, they reported higher perioperative complication rates amongst women who were $\geq 65$ years at the time of the procedure [26]. The mean age in our study was 62.6 years, and we observed no ileus, small bowel obstruction or need to convert to laparotomy, compared to the results of Turner et al. [26]. Our findings concur with those of Boudy et al. [27] who analyzed 47 women aged
70 or more, who constituted $24.6 \%$ of their study participants, and found comparable low frequencies of perioperative complications [27]. In view of the retrospective nature of the studies that have reported on LSC outcomes in different age groups and the lack of availability of the total number of women who presented with a significant a-POP during the studied periods we were not able to calculate their actual feasibility rates for undertaking this procedure in older age, and hence higher operative risk, groups [27,27,28,29]. In contrast, in our study LSC was offered to $85.5 \%$ of the women with a preoperative ASA-PS $\geq 3$. Moreover, 26 of the 36 women in our cohort ( $72.2 \%$ ) who were $\geq 70$ years, at the time of assessment, had an LSC for their a-POP repair.

We recognize that our study has some limitations. Firstly, the retrospective nature of the design and the potential risk of bias it might have introduced. However, we are confident that the

Table 2

Perioperative outcomes in study participants categorized based on their ASA-PS scores.

\begin{tabular}{|c|c|c|c|c|}
\hline & Total $\mathrm{N}=121$ & ASA PS $<3 \mathrm{~N}=75$ & ASA PS $\geq 3 \mathrm{~N}=46$ & $\mathrm{p}$ \\
\hline Operating time [min] mean (SD) & $124.0(28.3)$ & $123.3(26.2)$ & $125.8(31.6)$ & $0.55^{\mathrm{a}}$ \\
\hline Operating time more than 3 hours $\mathrm{N}(\%)$ & $4(3.3 \%)$ & $2(2.7 \%)$ & $2(4.3 \%)$ & $0.63^{\mathrm{b}}$ \\
\hline Blood loss $[\mathrm{ml}]$ mean (SD) & $182(84)$ & $178(92)$ & $179(70)$ & $0.53^{\mathrm{a}}$ \\
\hline Blood loss more than $300 \mathrm{ml} \mathrm{N}(\%)$ & $5(4.1 \%)$ & $5(6.7 \%)$ & $0(0.0 \%)$ & $0.16^{\mathrm{b}}$ \\
\hline Bladder injury $\mathrm{N}(\%)$ & $3(2.5 \%)$ & $2(2.7 \%)$ & $1(2.2 \%)$ & $1.00^{\mathrm{b}}$ \\
\hline Perioperative anaesthetic complications & $2(1.7 \%)$ & $1(1.3 \%)$ & $1(2.2 \%)$ & $1.00^{\mathrm{b}}$ \\
\hline Conversion to open laparotomy N (\%) & $0(0.0 \%)$ & $0(0.0 \%)$ & $0(0.0 \%)$ & $1.00^{\mathrm{b}}$ \\
\hline \multirow[t]{2}{*}{ Early complications [24] N (\%) } & $2(1.7 \%)$ & Grade II & Grade IIIB & $1.00^{\mathrm{b}}$ \\
\hline & & $1(1.3 \%)$ & $1(2.2 \%)$ & \\
\hline Hospital stay $>96$ hours $\mathrm{N}(\%)^{*}$ & $1(0.8 \%)$ & $0(0.0 \%)$ & $1(2.2 \%)$ & $0.38^{\mathrm{b}}$ \\
\hline Postoperative Urinary tract infection N (\%) & $8(6.6 \%)$ & $4(5.3 \%)$ & $4(8.7 \%)$ & $0.48^{\mathrm{c}}$ \\
\hline
\end{tabular}

a Wilcoxon Two Sample Test.

b Fisher's Exact Test.

c Chi-square Test.

* Due to the lack of community medical services following discharge, the normal length of hospital stay for an LSC is 96 hours. The case of grade IIIB complication related to a right ureteric kink treated with a subsequent temporary ureteral stent. 
Table 3

Follow-up at 3 months $(\mathrm{N}=116)$ and at 12 months $(\mathrm{N}=114)$.

\begin{tabular}{|c|c|c|c|c|c|c|}
\hline & \multicolumn{3}{|c|}{3 months follow-up } & \multicolumn{3}{|c|}{12 months follow-up } \\
\hline & ASA PS $<3 \mathrm{~N}=72$ & ASA PS $\geq 3 \mathrm{~N}=44$ & $\mathrm{p}$ & ASA PS $<3 \mathrm{~N}=72$ & ASA PS $\geq 3 \mathrm{~N}=42$ & $\mathrm{p}$ \\
\hline Postoperative complications related to mesh $\mathrm{C} 1-\mathrm{C} 7[\mathrm{~N} / \mathrm{N}](\%)[20]$ & $0 / 72(0.0 \%)$ & $0 / 44(0.0 \%)$ & $1.00^{\mathrm{a}}$ & $2 / 72(2.8 \%)^{*}$ & $1 / 42(2.4 \%)^{* *}$ & $1.00^{\mathrm{a}}$ \\
\hline Any failure $[\mathrm{N} / \mathrm{N}](\%)$ & $7 / 72(9.7 \%)$ & $3 / 44(6.8 \%)$ & $0.74^{\mathrm{a}}$ & $11 / 72(15.3 \%)$ & $6 / 42(14.3 \%)$ & $1.00^{\mathrm{a}}$ \\
\hline Failure in apical compartment Point $\mathrm{C} \geq-3[\mathrm{~N} / \mathrm{N}](\%)$ & $0 / 72(0.0 \%)$ & $0 / 44(0.0 \%)$ & $1.00^{\mathrm{d}}$ & $0 / 72(0.0 \%)$ & $0 / 42(0.0 \%)$ & $1.00^{\mathrm{a}}$ \\
\hline Failure in anterior compartment Point $\bar{B} a \geq-1[N / N](\%)$ & $3 / 72(4.2 \%)$ & $1 / 44(2.3 \%)$ & $1.00^{\mathrm{a}}$ & $5 / 72(6.9 \%)$ & $1 / 42(2.4 \%)$ & $0.41^{\mathrm{a}}$ \\
\hline Failure in posterior compartment Point $\mathrm{Bp} \geq-1[\mathrm{~N} / \mathrm{N}](\%)$ & $4 / 72(5.5 \%)$ & $2 / 44(4.3 \%)$ & $1.00^{\mathrm{a}}$ & $6 / 72(8.3 \%)$ & $5 / 42(11.9 \%)$ & $0.53^{\mathrm{a}}$ \\
\hline PGI-I $1,2[\mathrm{~N} / \mathrm{N}](\%)$ & $64 / 72(88.9 \%)$ & $38 / 44(86.4 \%)$ & $0.90^{\mathrm{b}}$ & $67 / 72(93.1 \%)$ & $40 / 42(95.2 \%)$ & $0.80^{\mathrm{b}}$ \\
\hline PGI-I $3[\mathrm{~N} / \mathrm{N}](\%)$ & $7 / 72(9.7 \%)$ & $5 / 44(11.3 \%)$ & & $3 / 72(4.2 \%)$ & $1 / 42(2.4 \%)$ & \\
\hline PGI-I $4[\mathrm{~N} / \mathrm{N}](\%)$ & $1 / 72(1.4 \%)$ & $1 / 44(2.3 \%)$ & & $1 / 72(1.4 \%)$ & $1 / 42(2.4 \%)$ & \\
\hline PGI-I $5[\mathrm{~N} / \mathrm{N}](\%)$ & $0 / 72(0.0 \%)$ & $0 / 44(0.0 \%)$ & & $1 / 72(1.4 \%)$ & $0 / 42(0.0 \%)$ & \\
\hline Post-op UDI mean (SD) & $35.7(41.2)$ & $30.9(39.2)$ & $0.35^{c}$ & $20.6(28.6)$ & $16.5(15.9)$ & $0.89^{c}$ \\
\hline Post-op POPDI mean (SD) & $33.1(37.6)$ & $30.5(38.9)$ & $0.51^{\mathrm{c}}$ & $26.2(34.8)$ & $19.8(18.6)$ & $0.88^{\mathrm{c}}$ \\
\hline Post-op CRADI mean (SD) & $36.4(45.0)$ & $37.7(42.0)$ & $0.74^{\mathrm{C}}$ & $35.3(41.9)$ & $27.8(27.2)$ & $0.99^{c}$ \\
\hline Post-op PFDI mean (SD) & $105.1(98.6)$ & $99.1(103.6)$ & $0.59^{c}$ & $82.1(93.0)$ & $64.1(45.5)$ & $0.99^{c}$ \\
\hline
\end{tabular}

a Fisher's Exact Test.

b Chi-square Test.

c Wilcoxon Two Sample Test.

Both cases were C1cS2 - one following supracervical hysterectomy + BSO and the other following a hysteropexy.

* C2aS2 following supracervical hysterectomy + BSO.

availability of an electronic patient database with unique codes for POP and the prospective collection of outcome measures as part of routine practice would have mitigated such risk. Moreover, it could be argued that a retrospective cohort design is best suited to assess clinical practice, which was an important aspect in evaluating the actual place of LSC in a-POP management. Secondly, we appreciate that this is a single center study evaluating a procedure that requires specific technical skills and hence might not be immediately generalizable elsewhere. Nevertheless, the real value of the study is the demonstration of what could be achieved if the required skills and setup are available. This issue is particularly relevant in view of the current FDA ban on the use of transvaginal mesh $[7,8]$. Finally, we have not assessed any neurological or cognitive outcomes because this information is not routinely collected in our unit at present. This might have been relevant, especially, when dealing with an older cohort of patients undergoing major surgical procedures. Although we do not have any evidence that any of the study participants had related complications, it might be prudent to consider evaluating such outcome measures in future studies. In contrast, the use of an objective validated measure to assess operative risk and the inclusion of core perioperative, urogynecologial and patient reported outcomes are major strengths to this study.

The effectiveness of LSC in the management of a-POP is well established. In this study we demonstrate it is feasible to perform an LSC in $90 \%$ of women requiring surgery for a significant a-POP. Moreover, the procedure was also safely performed in the cohort of women with compromised preoperative physical status.

\section{Declaration of Competing Interest}

The authors declare no conflicts of interest.

\section{Acknowledgements}

The study was funded by National Sustainability Program I (NPU I) Nr. LO1503 and Charles University Research Fund (Progres Q39). The funders did not have a role in the collection, analysis and interpretation of data and in the writing of the manuscript.

\section{Appendix A. Supplementary data}

Supplementary material related to this article can be found, in the online version, at doi:https://doi.org/10.1016/j.ejogrb.2019.10.049.

\section{References}

[1] Obinata D, Yamaguchi K, Ito A, Murata Y, Ashikari D, Igarashi T, et al. Lower urinary tract symptoms in female patients with pelvic organ prolapse: efficacy of pelvic floor reconstruction. Int J Urol 2014;21:301-7, doi:http://dx.doi.org $10.1111 /$ iju. 12281

[2] Handa VL, Cundiff G, Chang HH, Helzlsouer KJ. Female sexual function and pelvic floor disorders. Obstet Gynecol 2008;111:1045-52, doi:http://dx.doi. org/10.1097/AOG.0b013e31816bbe85.

[3] Augusto KL, LRPS Bezerra, Murad-Regadas SM, Vasconcelos Neto JA Vasconcelos CTM, Karbage SAL, et al. Defecatory dysfunction and fecal incontinence in women with or without posterior vaginal wall prolapse as measured by pelvic organ prolapse quantification (POP-Q). Eur J Obstet Gynecol Reprod Biol 2017;214:50-5, doi:http://dx.doi.org/10.1016/j. ejogrb. 2017.04.039.

[4] Practice bulletin No. 185. Obstet Gynecol 2017;130:e234-50, doi:http://dx.doi org/10.1097/AOG.0000000000002399.

[5] Maher C, Feiner B, Baessler K, Schmid C. Surgical management of pelvic organ prolapse in women. In: Maher $\mathrm{C}$, editor. Cochrane database syst. Rev. Chichester, UK: John Wiley \& Sons, Ltd; 2013, doi:http://dx.doi.org/10.1002/ 14651858.CD004014.pub5.

[6] Barber MD, Maher C. Apical prolapse. Int Urogynecol J 2013;24:1815-33, doi: http://dx.doi.org/10.1007/s00192-013-2172-1.

[7] Holt E. US FDA rules manufacturers to stop selling mesh devices. Lancet 2019;393:1686, doi:http://dx.doi.org/10.1016/S0140-6736(19)30938-9.

[8] Department of error. Lancet 2019;393:2124, doi:http://dx.doi.org/10.1016/ S0140-6736(19)31093-1.

[9] Maher C, Feiner B, Baessler K, Christmann-Schmid C, Haya N, Brown J. Surgery for women with apical vaginal prolapse. Cochrane Database Syst Rev 2016, doi: http://dx.doi.org/10.1002/14651858.CD012376.

[10] Rogers RG, Nolen TL, Weidner AC, Richter HE, Jelovsek JE, Shepherd JP, et al. Open sacrocolpopexy and vaginal apical repair: retrospective comparison of success and serious complications. Int Urogynecol J 2018;29:1101-10, doi: http://dx.doi.org/10.1007/s00192-018-3666-7.

[11] Rondini C, Braun H, Alvarez J, Urzúa MJ, Villegas R, Wenzel C, et al. High uterosacral vault suspension vs Sacrocolpopexy for treating apical defects: a randomized controlled trial with twelve months follow-up. Int Urogynecol J 2015;26:1131-8, doi:http://dx.doi.org/10.1007/s00192-015-2666-0.

[12] Svabik K, Martan A, Masata J, El-Haddad R, Hubka P. Comparison of vaginal mesh repair with sacrospinous vaginal colpopexy in the management of vaginal vault prolapse after hysterectomy in patients with levator ani avulsion: a randomized controlled trial. Ultrasound Obstet Gynecol 2014;43:365-71, doi:http://dx.doi.org/10.1002/uog.13305.

[13] Costantini E, Brubaker L, Cervigni M, Matthews CA, O'Reilly BA, Rizk D, et al Sacrocolpopexy for pelvic organ prolapse: evidence-based review and recommendations. Eur J Obstet Gynecol Reprod Biol 2016;205:60-5, doi: http://dx.doi.org/10.1016/j.ejogrb.2016.07.503.

[14] De Gouveia De Sa M, Claydon LS, Whitlow B, Dolcet Artahona MA Laparoscopic versus open sacrocolpopexy for treatment of prolapse of the apical segment of the vagina: a systematic review and meta-analysis. Int Urogynecol J 2016;27:3-17, doi:http://dx.doi.org/10.1007/s00192-015-2765-y.

[15] Tan PY, Stephens JH, Rieger NA, Hewett PJ. Laparoscopically assisted colectomy: a study of risk factors and predictors of open conversion. Surg Endosc 2008;22:1708-14, doi:http://dx.doi.org/10.1007/s00464-007-9702-1.

[16] Smazinka M, Kalis V, Havir M, Havelkova L, Ismail KM, Rusavy Z. Obesity and its long-term impact on sacrocolpopexy key outcomes (OBELISK). Int Urogynecol J 2019, doi:http://dx.doi.org/10.1007/s00192-019-04076-8. 
[17] Haylen BT, Maher CF, Barber MD, Camargo S, Dandolu V, Digesu A, et al. Erratum to: an International Urogynecological Association (IUGA) / International Continence Society (ICS) joint report on the terminology for female pelvic organ prolapse (POP). Int Urogynecol J 2016;27:655-84, doi:http://dx doi.org/10.1007/s00192-016-3003-y.

[18] American Society of Anesthesiologists. American society of anesthesiologists: ASA physical status classification system. Am Soc Anesthesiol Web Site Internet; 2014. . (Accessed April 2, 2016) https://www.asahq.org/resources/ clinical-information/asa-physical-status-classification-system.

[19] Barber MD, Kuchibhatla MN, Pieper CF, Bump RC. Psychometric evaluation of 2 comprehensive condition-specific quality of life instruments for women with pelvic floor disorders. Am J Obstet Gynecol 2001;185:1388-95, doi:http://dx. doi.org/10.1067/mob.2001.118659.

[20] Srikrishna S, Robinson D, Cardozo L. Validation of the Patient Globa Impression of Improvement (PGI-I) for urogenital prolapse. Int Urogynecol 2010;21:523-8, doi:http://dx.doi.org/10.1007/s00192-009-1069-5.

[21] Haylen BT, Freeman RM, Swift SE, Cosson M, Davila GW, Deprest J, et al. An International Urogynecological Association (IUGA) / International Continence Society (ICS) joint terminology and classification of the complications related directly to the insertion of prostheses (meshes, implants, tapes) \& grafts in female pelvic. Int Urogynecol J 2011;22:3-15, doi:http://dx.doi.org/10.1007/ s00192-010-1324-9.

[22] Dietz HP, Haylen BT, Broome J. Ultrasound in the quantification of female pelvic organ prolapse. Ultrasound Obstet Gynecol 2001;18:511-4, doi:http:// dx.doi.org/10.1046/j.0960-7692.2001.00494.x.
[23] Wong V, Guzman Rojas R, Shek KL, Chou D, Moore KH, Dietz HP. Laparoscopic sacrocolpopexy: how low does the mesh go? Ultrasound Obstet Gynecol 2017;49:404-8, doi:http://dx.doi.org/10.1002/uog.15882.

[24] Svabík K, Martan A, Masata J, El-Haddad R, Hubka P, Pavlikova M. Ultrasound appearances after mesh implantation-evidence of mesh contraction or folding? Int Urogynecol J 2011;22:529-33, doi:http://dx.doi.org/10.1007/ s00192-010-1308-9.

[25] Dindo D, Demartines N, Clavien P-A. Classification of surgical complications. Ann Surg 2004;240:205-13, doi:http://dx.doi.org/10.1097/01.sla.0000133083. 54934.ae.

[26] Turner LC, Kantartzis K, Lowder JL, Shepherd JP. The effect of age on complications in women undergoing minimally invasive sacral colpopexy. Int Urogynecol J 2014;25:1251-6, doi:http://dx.doi.org/10.1007/s00192-0142391-0.

[27] Boudy AS, Thubert T, Vinchant M, Hermieu JF, Villefranque V, Deffieux X. Outcomes of laparoscopic sacropexy in women over 70: a comparative study. Eur J Obstet Gynecol Reprod Biol 2016;207:178-83, doi:http://dx.doi.org/ 10.1016/j.ejogrb.2016.11.008.

[28] King SW, Jefferis H, Jackson S, Marfin AG, Price N. Laparoscopic uterovaginal prolapse surgery in the elderly: feasibility and outcomes. Gynecol Surg 2017;14:2, doi:http://dx.doi.org/10.1186/s10397-017-1000-x.

[29] Wijffels N, Cunningham C, Dixon A, Greenslade G, Lindsey I. Laparoscopic ventral rectopexy for external rectal prolapse is safe and effective in the elderly. Does this make perineal procedures obsolete? Color Dis 2011;13:5616, doi:http://dx.doi.org/10.1111/j.1463-1318.2010.02242.x. 